\title{
Promoting inclusion in clinical trials-a rapid review of the literature and recommendations for action
}

\author{
Danielle H. Bodicoat ${ }^{1}$, Ash C. Routen ${ }^{2,3}$ (D) Andrew Willis ${ }^{2,3}$, Winifred Ekezie ${ }^{2,3}$, Clare Gillies ${ }^{3}$, Claire Lawson ${ }^{5}$,
} Thomas Yates ${ }^{3,4}$, Francesco Zaccardi ${ }^{5}$, Melanie J. Davies ${ }^{3,4,6}$ and Kamlesh Khunti ${ }^{2,3,4,5^{*}}$

\begin{abstract}
Background: Without inclusion of diverse research participants, it is challenging to understand how study findings will translate into the real world. Despite this, a lack of inclusion of those from under-served groups in research is a prevailing problem due to multi-faceted barriers acting at multiple levels. Therefore, we rapidly reviewed international published literature, in relation to clinical trials, on barriers relating to inclusion, and evidence of approaches that are effective in overcoming these.

Methods: A rapid literature review was conducted searching PubMed for peer-reviewed articles that discussed barriers to inclusion or strategies to improve inclusion in clinical trial research published between 2010 and 2021. Grey literature articles were excluded.

Results: Seventy-two eligible articles were included. The main barriers identified were language and communication, lack of trust, access to trials, eligibility criteria, attitudes and beliefs, lack of knowledge around clinical trials, and logistical and practical issues. In relation to evidence-based strategies and enablers, two key themes arose: [1] a multi-faceted approach is essential [2]; no single strategy was universally effective either within or between trials. The key evidence-based strategies identified were cultural competency training, community partnerships, personalised approach, multilingual materials and staff, communication-specific strategies, increasing understanding and trust, and tackling logistical barriers.

Conclusions: Many of the barriers relating to inclusion are the same as those that impact trial design and healthcare delivery generally. However, the presentation of these barriers among different under-served groups may be unique to each population's particular circumstances, background, and needs. Based on the literature, we make 15 recommendations that, if implemented, may help improve inclusion within clinical trials and clinical research more generally. The three main recommendations include improving cultural competency and sensitivity of all clinical trial staff through training and ongoing personal development, the need to establish a diverse community advisory panel for ongoing input into the research process, and increasing recruitment of staff from under-served groups. Implementation of these recommendations may help improve representation of under-served groups in clinical trials which would improve the external validity of associated findings.
\end{abstract}

Keywords: Equality, Diversity, Inclusion, Ethnicity, Clinical research, Clinical trial, Review

\footnotetext{
* Correspondence: kk22@leicester.ac.uk

${ }^{2}$ Centre for Ethnic Health Research, University of Leicester, Leicester General Hospital, Leicester, UK

${ }^{3}$ Diabetes Research Centre, University of Leicester, Leicester General Hospital, Leicester, UK

Full list of author information is available at the end of the article
}

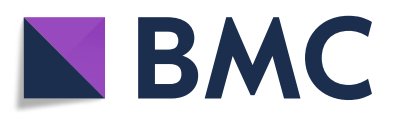

(c) The Author(s). 2021 Open Access This article is licensed under a Creative Commons Attribution 4.0 International License, which permits use, sharing, adaptation, distribution and reproduction in any medium or format, as long as you give appropriate credit to the original author(s) and the source, provide a link to the Creative Commons licence, and indicate if changes were made. The images or other third party material in this article are included in the article's Creative Commons licence, unless indicated otherwise in a credit line to the material. If material is not included in the article's Creative Commons licence and your intended use is not permitted by statutory regulation or exceeds the permitted use, you will need to obtain permission directly from the copyright holder. To view a copy of this licence, visit http://creativecommons.org/licenses/by/4.0/. The Creative Commons Public Domain Dedication waiver (http://creativecommons.org/publicdomain/zero/1.0/) applies to the data made available in this article, unless otherwise stated in a credit line to the data. 


\section{Background}

The importance of inclusion in health and social care research has gained increasing recognition, as further highlighted in the COVID-19 pandemic [1]. Without participants from a broad range of backgrounds (age, gender, ethnicity, comorbidities), it is not possible to understand how study findings will translate into real-world application, and this is particularly true for clinical trials.

The term under-served group refers to segments of the population who are represented in health research at lower levels than would be expected from population estimates [2]. Groups considered under-served [2] in clinical research are heterogenous and are often crudely considered in terms of basic characteristics, such as ethnicity, disability, or age. But what constitutes underserved is complex and context-specific-and may be disease or study-specific [2]. General examples of under-served groups are often defined by demographic, social, or economic factors; health factors; and/or disease-specific characteristics [2]. Working-age populations, for example, are often under-served in research, despite not typically being considered as under-served in other settings. Despite the ethical and scientific implications of a lack of inclusion in research, it remains a widespread issue [3-6], as demonstrated in recent COVID-19-specific trials [7].

For example, ethnic minority involvement in health and social care research mostly occurs during the research design phase and least in data analysis and interpretation [8]. The majority of evidence on ethnic minority inclusion in clinical research is from the USA, with relatively little other research globally [9]. Furthermore, defining the true scale of the issue is made difficult by a lack of reporting relating to protected characteristics. For example, a systematic review found that of 1518 COVID-19-related studies registered on ClinicalTrials.gov, only six reported collecting data on ethnicity [10]. There are numerous inter-related reasons for the lack of diversity among clinical research participants, not least, that recognition and acceptance of the issue is relatively new compared with long-standing practices of research. Barriers to successful inclusion (i.e. increased representation of under-served groups in clinical trial populations) can broadly be considered to coalesce into issues relating to communication between researchers and participants, how trials are designed and delivered, differing agendas of research teams and participant groups, and a lack of trust in the research process $[11,12]$.

Given the COVID-19 pandemic has demonstrated the necessity of improving inclusion in clinical research and the UK government's call for increased diversity in clinical research, there is a pressing need for understanding and education around barriers to inclusion in clinical research and improvement strategies. In particular, the current and ongoing COVID-19 trials require up-to-date and actionable information on how to improve inclusion in their cohorts. Therefore, there is a distinct necessity for a rapid review of the literature on barriers and enablers of inclusion in clinical research.

Consequently, the primary purpose of this paper was to review international published literature and produce a high-level summary of existing evidence and studies that consider the specific barriers in relation to inclusion in clinical trials and evidence of approaches that are effective in overcoming these. A second aim was to make recommendations for how clinical researchers can support trials to be diverse and inclusive.

\section{Methods}

Design

A rapid review is a method of knowledge synthesis that accelerates the process of conducting a systematic review, by simplifying or omitting various stages of the process (e.g. search terms and inclusion criteria, data extraction, and bias assessment). This streamlining of the traditional systematic review methodology permits the production of evidence synthesis in a timely/resource-efficient manner for use by stakeholders. A rapid review was conducted over a 3-week period, from 13/03/2021 to $30 / 03 / 2021$.

\section{Search strategy}

A search of published literature was conducted in PubMed using the search terms detailed in Additional File 1. The search was limited to papers published in English language from 1 January 2010 onwards to ensure that the findings represented the contemporary research landscape. Reference lists of included articles were handsearched for additional relevant literature.

\section{Eligibility criteria, study selection, and quality assessment} The inclusion criteria included peer-reviewed articles that discussed barriers to inclusion or strategies to improve inclusion in clinical trial research published between January 2010 and March 2021. Grey literature articles were excluded.

Title and abstract screening of articles identified from electronic searches against the inclusion criteria was performed by a single reviewer (DHB). Full-text articles were also screened for inclusion by a single reviewer (DHB). Quality assessment of included articles was not undertaken to facilitate the rapid review of evidence.

\section{Data synthesis}

The following data were extracted: first author, year, country, study type/design, number of trials, and number of participants (some studies reported both because they 
reported on their approaches over multiple trials), underserved groups considered, conditions considered (e.g. sleep, asthma, cancer, breastfeeding), and findings/information relating to enabling strategies or barriers. Findings from included articles were synthesised using tables and a narrative summary by a single reviewer (DHB), following a narrative, descriptive synthesis approach. Findings were summarised into two key themes relating to barriers to inclusion, and strategies used to overcome these, with a number of sub-themes within each overarching theme.

\section{Results}

\section{Screening results}

A total of 1861 results were returned from the search and screened for inclusion. Overall, 72 articles were included within this review (see Fig. 1 for screening data). The majority of the included articles (74\%) were from the USA and a third focused on cancer trials (33\%). In relation to the type of under-served groups included, half of all articles (50\%) focused on inclusion issues relating to ethnic minority populations. The remainder focused on general under-served groups, children and young people, adolescents, women, and others (e.g. deaf, transgender). Sixty-one (85\%-see Additional File 1 for more details) of the included articles reported on strategies to improve inclusion (of which $n=13$ also included information on barriers). Eleven articles reported on barriers to inclusion alone. The 72 papers are included within the "Results" section, Additional File 1, or a combination of these.

\section{Barriers to inclusion}

A consistent theme across the literature is that many of the barriers relating to inclusion are the same as those that impact trial design and delivery [13]. The nuance is around how these barriers present among different,

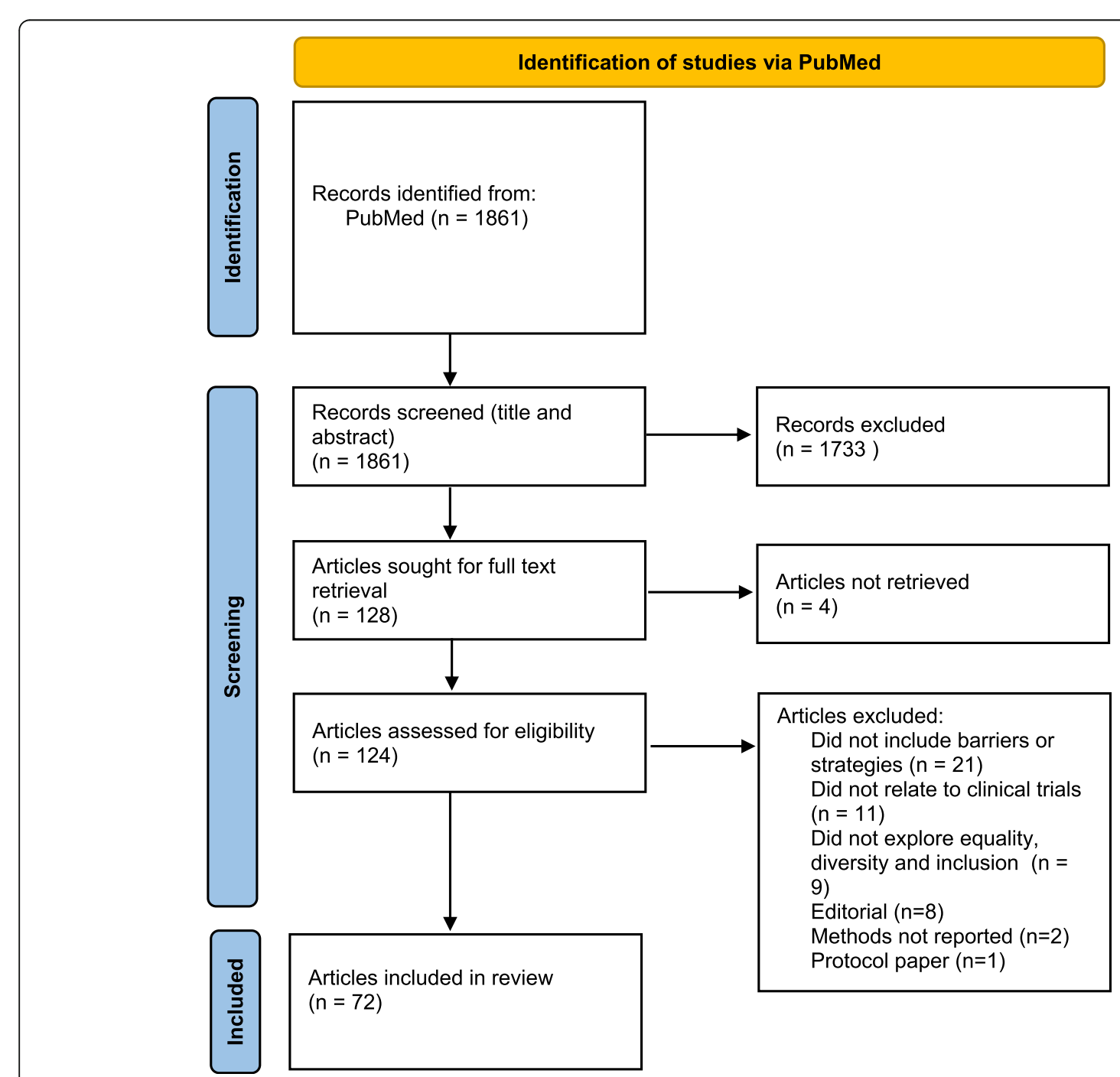

Fig. 1 Screening and inclusion of identified articles 
under-served groups, which is often unique to each population's particular circumstances, background, beliefs, and needs. Barriers are summarised below.

\section{Language and communication}

This well-known barrier to inclusion, particularly among recent migrant ethnic groups, remains an ongoing issue. In trials conducted in the USA and Europe, being unable to speak and/or read English is a common barrier faced by individuals [14]. Closely related to this is the ability to speak and/or read English to a certain level, without fully comprehending the meaning of everything that is said or written [15]. There is also the further issue of how this decision is made, i.e. who decides whether someone speaks good enough English to take part and what criteria are used. Importantly, language barriers can also be viewed as a failure to show respect to potential participants if the information has not been made available in a culturally relevant and accessible language format [16].

Finally, language/literacy barriers do not only apply to migrant ethnic groups, as other under-served populations also experience language/literacy barriers due to a range of issues such as disability or the impact of lack of education/access to education on literacy. For example, deaf individuals may need support with sign language $[17,18]$.

Poor communication was another common barrier that was predominantly identified in studies with groups $[19,20]$. This may relate to literacy generally and also to health literacy more specifically [15]. Similarly, studies in children need age-appropriate communication [21].

\section{Lack of trust}

For potential participants, having a lack of trust in research, doctors, investigators, drugs, and the medical industry was a recurring theme across the literature [14-16, $19,20,22-24]$. This may arise from previous bad experiences and previous severe adverse events in reported studies [25] and was often compounded by related beliefs or fears [23]. For example, older adults may fear that experimentation could damage their health [26] or that participation would not benefit younger generations [27].

\section{Access to trials}

A lack of access to relevant clinical trials manifested in a number of different ways. First, a lack of information about trials for which potential participants are eligible and available is a barrier [22, 23, 28]. This may particularly be the case for people without a usual place for care, who are also often not eligible for relevant trials [29]. Similarly, the inability to access the healthcare or research centre was a barrier [20, 28, 30]. Not being invited to eligible trials was another access-related barrier
[31]. Finally, other practical factors preventing access to trials more generally remain important in under-served groups, such as recruitment competition for other studies and lack of recruitment staff [32].

\section{Eligibility criteria}

Some studies highlighted that inclusion/exclusion criteria often disproportionately exclude people in underserved groups, including older adults, pregnant women, obese individuals, people with existing/multiple chronic conditions (multi-morbidity), and people with severe mental illness [27, 28, 32]. This exclusion may be explicit; for example, lack of capacity to consent is a common exclusion criterion that means individuals without this capacity are denied the opportunity to participate in research [33]. It also means there is consequently a limited evidence base regarding health interventions in this population [33]. On the other hand, eligibility criteria may indirectly exclude some populations to a greater extent than others; for example, exclusion criterion may be more prevalent in some ethnic minority groups than in White Europeans, such as chronic diseases [34].

\section{Attitudes and beliefs}

This barrier can present in many different ways and is often context and populationspecific. Examples that arise in the literature include no personal or family history of the condition under study [29]; stigma surrounding the condition under study [13, 16, 24]; beliefs among older adults that they were too old to participate in trials [26]; concerns around immigration status for some ethnic minority populations [23]; concerns about side effects or taking an experimental medicine [27, 35]; stress, fatalism, and a conservative attitude to risk-taking among Asian women [25]; religious beliefs [30]; "Guinea pig" perceptions [36]; not feeling comfortable, welcome, or respected [36]; privacy concerns [23]; and negative attitudes to clinical trials [30]. In addition, not only the individual's own beliefs and attitudes, but also those of their friends and families can prevent under-served groups from taking part in trials, as lack of social approval was found to be an important barrier $[27,28,36,37]$.

\section{Lack of knowledge around clinical trials}

There were a large number of studies that identified a lack of understanding about clinical trials as a barrier in a range of populations, particularly among ethnic minorities $[14,19,22,30]$. Examples of where this lack of knowledge/information was apparent included the trial process such as during recruitment or the collection of data $[22,23]$. 


\section{Logistical and practical issues}

Logistical and practical barriers were particularly prevalent among under-served groups studied [15], including lack of transport $[16,20,28,30,32]$, time [16, 22, 24, 28 ], additional visits/tests [25], indirect costs associated with participating [23], childcare [20,30], work responsibilities [20], and issues related to the condition under study, e.g. pregnancy or drug abstinence $[24,25,28]$.

\section{Other barriers}

Aside from these key barriers that were commonly referred to across the literature, single papers also highlighted the following barriers which may be relevant to clinical trials, including lack of follow-up during the recruitment process [32], lack of investigator/study team outreach to communities [28], challenging patient social and structural factors (e.g. homelessness) [24], difficulty locating eligible patients in clinic (HIV-related study) [24], and unavailability of research staff out-of-hours [35].

\section{Evidence-based strategies and enablers}

The main evidence-based strategies and enablers to improving inclusion identified through the literature search are fully detailed in Additional File 1. The remainder of this section summarises the key evidence-based strategies identified within the literature.

\section{Cultural competency training}

There was a range of evidence suggesting that inclusion in trials was improved when staff had received specific training on that topic $[13,15,19,38-46]$. This may include teaching study staff about cultural humility, existing health inequities, and the background and context as to how these have arisen [44], including previous research abuses (e.g. deception and mistreatment in research, such as the Tuskegee syphilis study). Acknowledgement of these was found to be important, particularly for African Americans [47]. It was also noted that applying knowledge of culturally important practices was also beneficial $[16,42,48]$.

\section{Community partnerships}

A recurring theme was that strategies that closed the gap between the study team and the community were very effective $[17,19,20,38,42,46,49-53]$, particularly community-based participatory research (CBPR) approaches $[54,55]$. Some specific strategies around this included the use of a community advisory board [38, 46]; patient advocates/navigators, including to recruit participants $[38,49,56]$; ongoing partnerships with community members, leaders, groups, and organisations $[19,20,38$, $41,42,49,50,52,56,57]$; direct outreach to community participants followed by electronic health record data for clinical information and follow-up [58]; oversight by a community panel [20]; and consultation with community members regarding study resources [49].

\section{Personalised approach}

Emphasis has been placed on strategies that lead to a more personal approach within clinical trials. These strategies may help people feel that they are seen both as an individual, as well as part of the groups with which they identify. Examples include building good rapport and relationships with participants $[48,51,59,60]$, individual communication styles [60], a human (i.e. not automated) phone call in the participant's preferred language [61], birthday and holiday cards [57], thank you letters [53, 57], acknowledgement certificates [53], and relationship-centred recruitment and retention [43].

\section{Multilingual materials and staff}

A number of studies directly overcame language barriers for non-English speakers by providing bilingual staff [20, 42, 47, 52, 57, 59, 62], materials in non-English languages $[20,42,49,57,62,63]$, and/or an interpreter [42, 63]. Similarly, in a study conducted with deaf individuals, a variety of contact methods (video call and email) and materials in both sign language video and written English were found to help [17]. Many studies explicitly aimed to recruit study staff from under-served groups so that research teams are representative of the people being recruited, especially if from the local community [13, $17,39,47-50,52]$, and some even matched study team members and participants on ethnicity [54].

\section{Communication-specific strategies}

Aside from language, a number of other strategies specifically related to communication have been implemented, including community providers or physicians sending letters of support to potential participants prior to study contact $[42,49,62]$, mass mailing [64, 65], third party contact obtained at enrollment [59], out-of-hours contact [52, 59], keeping phone calls short [59], reminder calls or postcards $[57,59]$, regular study updates [57], maintaining up-to-date information [59], using social media for recruitment and retention (particularly Facebook) [56, 66], appropriate readability/simplified English materials [20, 44, 47], patient-centred/preferred communication methods [20], use of multimedia [15, $30]$, and appointment cancellations followed up vigorously [67].

\section{Increasing understanding and trust}

In order to tackle barriers related to a lack of understanding or trust in clinical trials, several studies provided educational sessions for communities [23, 39, 47, $49,50,65,68]$, with one successfully employing teach/ teach-back methodology [20]. Others aimed to build 
trust through communications [50] or by sharing patient safety information [47]. Using social proof was also a key strategy for improving trust either through participant testimonials [56,63] or friends and family referrals $[30,64,69]$.

\section{Tackling logistical barriers}

Multiple logistical barriers to recruitment and retention exist in clinical trials, and they remain a pertinent issue in under-served groups. Strategies that attempt to overcome these include flexible timings and locations of study visits $[16,20,70]$, including home-based assessments [48]; providing childcare [42]; transport [24, 42]; and reducing costs associated with trial participation [42].

\section{Additional strategies}

Aside from these key strategies that were commonly referred to across the literature, some articles also highlighted the following enabling practices which may be relevant to clinical trials, including leadership from organisations and management around inclusion [38, 40, 42]; partnering with local healthcare centres/practices and clinical staff $[20,35,43,44,49,67,71]$; nondiscriminatory inclusion/exclusion criteria $[35,48,53$, 64, 72]; recruitment targets for diverse groups [48, 52, 53, 64, 72]; electronic database to track participants throughout the study [44]; two-step method of collecting sex at birth and gender identity on data collection forms [46]; alleviating burdensome data collection [73]; studybranded items with study information, e.g. fridge magnets [53, 59]; and family involvement $[42,48]$.

\section{Discussion}

\section{Summary of main findings}

This rapid review aimed to synthesise the international published literature on studies that consider the specific barriers in relation to inclusion in clinical trials, and evidence of approaches that have been effective in overcoming these. It is notable that the majority of publications around equality, diversity, and inclusion (EDI) relate to ethnicity, whereas there is less contemporary literature around other protected characteristics. Furthermore, the majority of the literature is from the USA and focuses on cancer trials. The main barriers identified in the literature included language and communication, lack of trust, access to trials, eligibility criteria, attitudes and beliefs, lack of knowledge around clinical trials, and logistical and practical issues. The primary strategies to improve inclusion in clinical trials identified in the literature relate to staff cultural competency training, building community partnerships, taking a personalised approach, utilising multilingual materials and staff, communication-specific strategies, increasing understanding and trust, and tackling logistical barriers.

\section{Recommendations for policy and practice}

There were two important points that arose from reviewing this literature. First, a multi-faceted approach is essential. The vast majority of studies found that multiple strategies were required to improve inclusion [13, $16,17,19,20,22,24,30,35,38-40,42-45,47-53,56$, $57,59,60,62-64,67,72,73]$. Furthermore, most successful strategies had elements that operated at different levels, such as within the study team and within the community of interest.

Second, no single strategy was universally effective either within or between trials. For example, many studies found that providing incentives of some form was an enabler [16, $52,57,59,67]$, whereas this was directly tested in one study that found no benefit of incentives [74]. Similarly, other studies found that strategies that worked well at one site did not necessarily work well at another site [52]. Effective strategies are also likely to be population-specific and may be contradictory. It is therefore important to consider the target population when choosing an approach. For example, a study of South Asians found that it was important to refer to gender throughout communications and have separate versions for men and women [42], whereas transgender individuals may have different preferences [46].

From reviewing the literature, we have made a series of 15 recommendations (Table 1 ) that may help improve inclusion within clinical trials and clinical research. The recommendations focus on 6 areas/strategies: [1] research staff covering the need for improving cultural competency and sensitivity of all clinical trial staff through training and ongoing learning, and the need to increase recruitment of staff from under-served groups [2]; communication including personalisation of communications, providing alternative languages, having video calling as an option, using social testimony, offering community outreach, and extending office hours [3]; establishing a diverse community advisory panel [4]; developing public education about clinical trials [5]; feasibility and or identification including examining demographics of excluded populations, encouraging the use of sites with high enrollment of underserved groups, exploring linkages with non-healthcare data sources, and creating a local registry of interested under-served groups; and [6] collecting participant data on both sex at birth and gender identity. Although much of the literature identified in this rapid review is drawn from the USA, our recommendations are general principles that are broadly applicable to similar clinical and healthcare contexts. Implementation of these recommendations may help improve representation of under-served groups in clinical trials which would lead to greater external validity of associated findings. Without external validity of research-informed treatments and services, delivering equitable high-quality care within healthcare systems is impaired. 


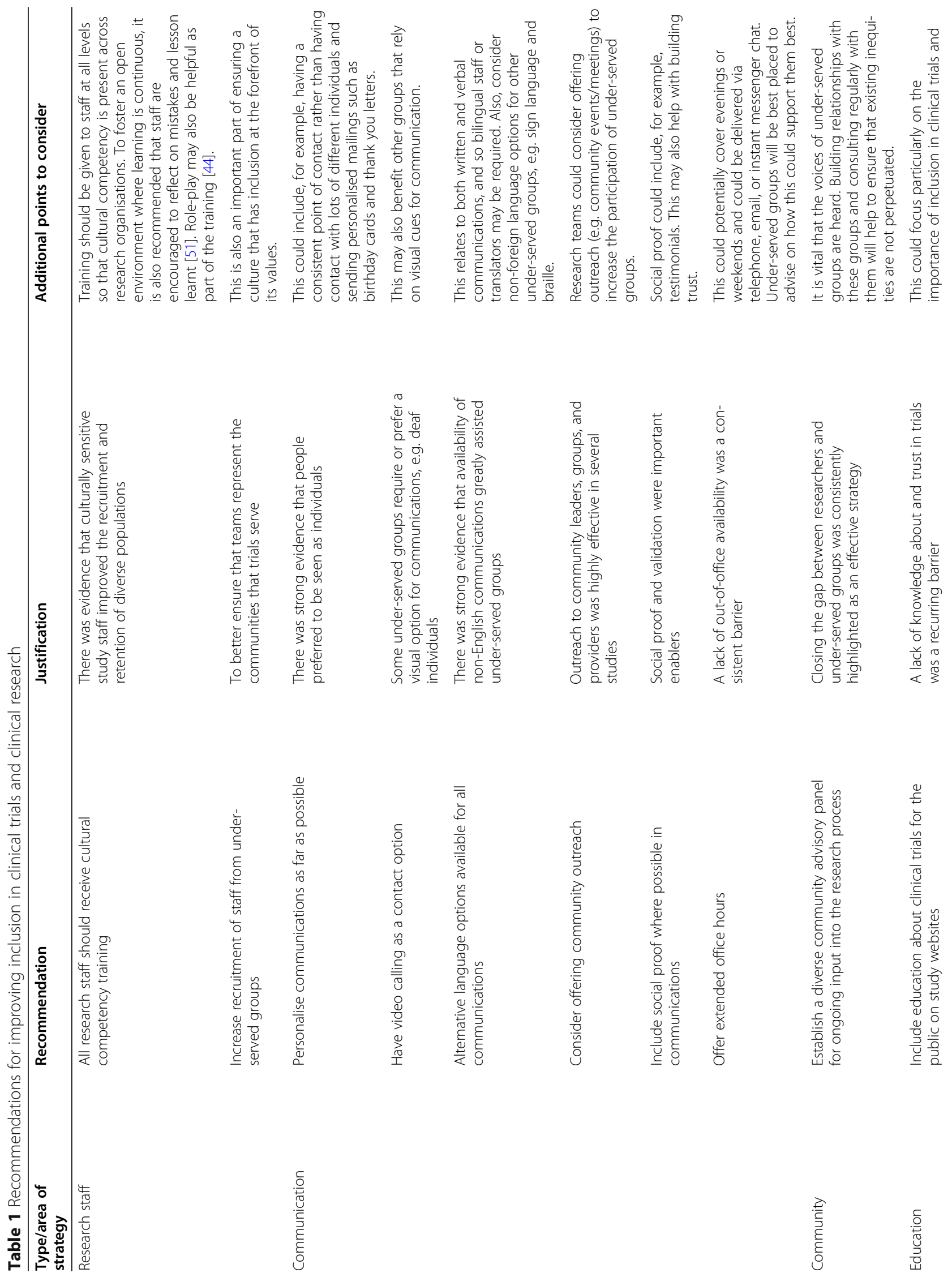




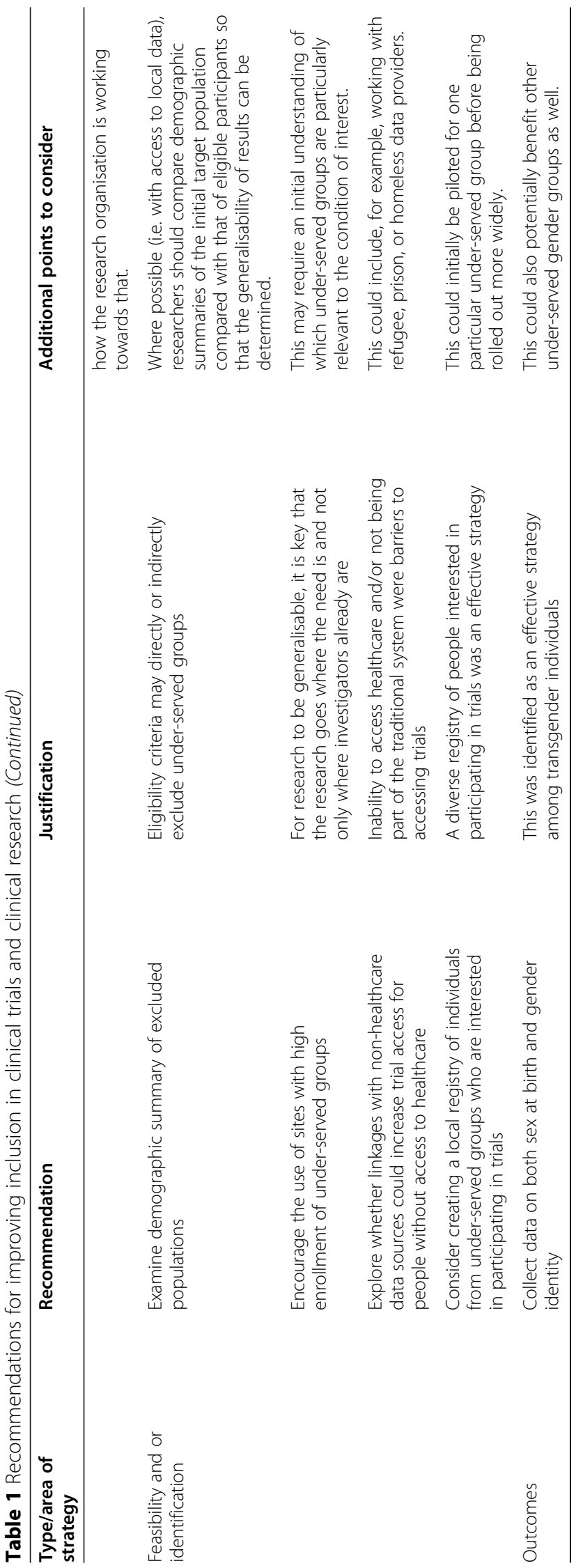




\section{Strengths and limitations}

A key strength of this rapid review is the identification of a large evidence base on barriers and enablers to inclusion, which can be used to inform practice in clinical research. There are, however, limitations of the rapid review approach. By searching a single electronic database and only including peer-reviewed publications, potentially relevant publications may have been omitted, therefore, introducing some bias. Examples of studies that would be systematically excluded from the search are grey literature, as well as studies that include barriers or enablers as secondary aspects that are not clearly searchable within the title or abstract. However, it is unlikely that the barriers or enablers in such studies would be systematically different from those identified in this search, and so the results are presumed to be unbiased. In addition, the use of a single reviewer to ensure consistency and reduce the time required for this review may have also introduced bias. A further limitation is the lack of a quality assessment of included studies. By not appraising the methodological quality of studies, the quality of the evidence on which our findings are based is not known.

\section{Conclusion}

This review identified a range of barriers relating to inclusion, and the available literature suggests these issues may manifest differently depending on the population. A number of strategies to overcome these barriers to inclusion were identified, but the implementation of multiple approaches and at differing levels may be required. Based on the available evidence, we made a series of recommendations that, if implemented, may help improve inclusion within clinical trials and clinical research.

\section{Supplementary Information}

The online version contains supplementary material available at https://doi. org/10.1186/s13063-021-05849-7.

Additional file 1. EDI Rapid Review Paper Author Responses

\section{Authors' contributions}

The review concept was conceived by $\mathrm{KK}$ and $\mathrm{DHB}$, with critical input from AW, WE, CG, CL, TY, FZ, and MJD. The review was conducted by DHB. The manuscript was drafted by $\mathrm{AR}$ and $\mathrm{DHB}$. All other authors contributed to critical revisions of the manuscript.

\section{Funding}

KK, AR, AW, and WE are supported by the National Institute for Health Research (NIHR) Applied Research Collaboration East Midlands (ARC EM). KK and MD are supported by NIHR Leicester Biomedical Research Centre (BRC). The views expressed are those of the authors and not necessarily those of the NIHR, NHS, or the Department of Health and Social Care. This review was originally commissioned and funded by NHS DigiTrials.

\section{Availability of data and materials}

The datasets used and/or analysed during the current study are available from the corresponding author on reasonable request.

\section{Declarations}

Ethics approval and consent to participate

Not applicable

Consent for publication

Not applicable

\section{Competing interests}

KK is a director of The Centre for Ethnic Health Research at the University of Leicester, is a trustee of the charity South Asian Health Foundation and cochair of its diabetes working group, and is chair of the SAGE ethnicity subgroup .

\section{Author details}

${ }^{1}$ Independent Researcher, Leicester, UK. ${ }^{2}$ Centre for Ethnic Health Research, University of Leicester, Leicester General Hospital, Leicester, UK. ${ }^{3}$ Diabetes Research Centre, University of Leicester, Leicester General Hospital, Leicester, UK. ${ }^{4}$ NIHR Leicester Biomedical Research Centre, Leicester General Hospital, Leicester, UK. ${ }^{5}$ Leicester Real World Evidence Unit, Diabetes Research Centre, University of Leicester, Leicester General Hospital, Leicester, UK. ' Leicester Diabetes Centre, University Hospitals of Leicester NHS Trust, Leicester, UK.

Received: 29 July 2021 Accepted: 20 November 2021

Published online: 04 December 2021

\section{References}

1. Treweek S, Forouhi NG, Narayan KMV, Khunti K. COVID-19 and ethnicity: who will research results apply to? Lancet. 2020;395(10242):1955-7. https:// doi.org/10.1016/S0140-6736(20)31380-5.

2. NIHR. Improving inclusion of under-served groups in clinical research: guidance from INCLUDE project 2020 [August 2020 v1.0:[Available from: https://www.nihr.ac.uk/documents/improving-inclusion-of-under-servedgroups-in-clinical-research-guidance-from-include-project/25435.

3. Mason S, Hussain-Gambles M, Leese B, Atkin K, Brown J. Representation of South Asian people in randomised clinical trials: analysis of trials' data. BMJ. 2003;326(7401):1244-5. https://doi.org/10.1136/bmj.326.7401.1244.

4. Bartlett C, Davey P, Dieppe P, Doyal L, Ebrahim S, Egger M. Women, older persons, and ethnic minorities: factors associated with their inclusion in randomised trials of statins 1990 to 2001. Heart. 2003;89(3):327-8. https:// doi.org/10.1136/heart.89.3.327.

5. Heiat A, Gross CP, Krumholz HM. Representation of the elderly, women, and minorities in heart failure clinical trials. Arch Intern Med. 2002;162(15):16828. https://doi.org/10.1001/archinte.162.15.1682

6. Hall WD. Representation of blacks, women, and the very elderly (aged $>$ or $=80$ ) in 28 major randomized clinical trials. Ethn Dis. 1999;9(3):333-40.

7. Gardiner T, Cooke G, Fidler S, Cooper N, Young L. The under-representation of BAME patients in the COVID-19 Recovery trial at a major London NHS Trust. J Infect. 2020:82(4):84-123. https://doi.org/10.1016/j.jinf.2020.11.004.

8. Dawson S, Campbell SM, Giles SJ, Morris RL, Cheraghi-Sohi S. Black and minority ethnic group involvement in health and social care research: a systematic review. Health Expect. 2018;21(1):3-22. https://doi.org/10.1111/ hex.12597.

9. Iqbal H, West J, Haith-Cooper M, McEachan RRC. A systematic review to identify research priority setting in Black and minority ethnic health and evaluate their processes. PLOS ONE. 2021;16(5):e0251685. https://doi.org/1 0.1371/journal.pone.0251685.

10. Pan D, Sze S, Minhas JS, Bangash MN, Pareek N, Divall P, et al. The impact of ethnicity on clinical outcomes in COVID-19: a systematic review. EClinicalMedicine. 2020;23:100404. https://doi.org/10.1016/j.eclinm.2020.100404.

11. Witham MD, Anderson E, Carroll C, Dark PM, Down K, Hall AS, et al. Developing a roadmap to improve trial delivery for under-served groups: results from a UK multi-stakeholder process. Trials. 2020;21(1):694. https:// doi.org/10.1186/s13063-020-04613-7.

12. Harrison R, Walton M, Chitkara U, Manias E, Chauhan A, Latanik M, et al. Beyond translation: engaging with culturally and linguistically diverse consumers. Health Expect. 2020;23(1):159-68. https://doi.org/10.1111/hex.12984.

13. Bass SB, D'Avanzo P, Alhajji M, Ventriglia N, Trainor A, Maurer $L$, et al. Exploring the engagement of racial and ethnic minorities in HIV treatment and vaccine clinical trials: a scoping review of literature and implications for 
future research. AIDS Patient Care STDS. 2020;34(9):399-416. https://doi. org/10.1089/apc.2020.0008.

14. Byrne MM, Tannenbaum SL, Glück S, Hurley J, Antoni M. Participation in cancer clinical trials: why are patients not participating? Med Decis Making 2014;34(1):116-26. https://doi.org/10.1177/0272989X13497264.

15. Hughson JA, Woodward-Kron R, Parker A, Hajek J, Bresin A, Knoch U, et al. A review of approaches to improve participation of culturally and linguistically diverse populations in clinical trials. Trials. 2016;17(1):263. https://doi.org/1 0.1186/s13063-016-1384-3.

16. Rooney LK, Bhopal R, Halani L, Levy ML, Partridge MR, Netuveli G, et al. Promoting recruitment of minority ethnic groups into research: qualitative study exploring the views of South Asian people with asthma. J Public Health (Oxf). 2011;33(4):604-15. https://doi.org/10.1093/pubmed/fdq100.

17. Anderson ML, Wolf Craig KS, Ziedonis DM. Barriers and facilitators to deaf trauma survivors' help-seeking behavior: lessons for behavioral clinical trials research. J Deaf Stud Deaf Educ. 2017;22(1):118-30. https://doi.org/10.1093/ deafed/enw066

18. Isaacs T, Murdoch J, Demjén Z, Stevenson F. Examining the language demands of informed consent documents in patient recruitment to cancer trials using tools from corpus and computational linguistics. Health (London). 2020:1363459320963431.

19. Boden-Albala B, Carman H, Southwick L, Parikh NS, Roberts E, Waddy S, et al. Examining barriers and practices to recruitment and retention in stroke clinical trials. Stroke. 2015;46(8):2232-7. https://doi.org/10.1161/ STROKEAHA. 114.008564.

20. Fischer SM, Kline DM, Min SJ, Okuyama S, Fink RM. Apoyo con Cariño: strategies to promote recruiting, enrolling, and retaining Latinos in a cancer clinical trial. J Natl Compr Canc Netw. 2017;15(11):1392-9. https://doi.org/10. 6004/jnccn.2017.7005.

21. Le Rouzic MA, Claudot F. Characteristics of parental decision-making for children with advanced cancer who are offered enrollment in early-phase clinical trials: a systematic review. Pediatr Hematol Oncol. 2020;37(6):500-29. https://doi.org/10.1080/08880018.2020.1759738.

22. Clark LT, Watkins L, Piña IL, Elmer M, Akinboboye O, Gorham M, et al. Increasing diversity in clinical trials: overcoming critical barriers. Curr Probl Cardiol. 2019:44(5):148-72. https://doi.org/10.1016/..cpcardiol.2018.11.002.

23. Cunningham-Erves J, Barajas C, Mayo-Gamble TL, McAfee CR, Hull PC, Sanderson $\mathrm{M}$, et al. Formative research to design a culturally-appropriate cancer clinical trial education program to increase participation of African American and Latino communities. BMC Public Health. 2020;20(1):840. https://doi.org/10.1186/s12889-020-08939-4.

24. Hoffman KA, Baker R, Kunkel LE, Waddell EN, Lum PJ, McCarty D, et al. Barriers and facilitators to recruitment and enrollment of HIV-infected individuals with opioid use disorder in a clinical trial. BMC Health Serv Res. 2019;19(1):862. https://doi.org/10.1186/s12913-019-4721-x.

25. Lee GE, Ow M, Lie D, Dent R. Barriers and facilitators for clinical trial participation among diverse Asian patients with breast cancer: a qualitative study. BMC Womens Health. 2016;16(1):43. https://doi.org/10.1186/s12905-016-0319-1.

26. Bloch $\mathrm{F}$, Charasz N. Attitudes of older adults to their participation in clinical trials: a pilot study. Drugs Aging. 2014;31(5):373-7. https://doi.org/10.1007/s4 0266-014-0168-2.

27. Javid SH, Unger JM, Gralow JR, Moinpour CM, Wozniak AJ, Goodwin JW, et al. A prospective analysis of the influence of older age on physician and patient decision-making when considering enrollment in breast cancer clinical trials (SWOG S0316). Oncologist. 2012;17(9):1180-90. https://doi.org/1 0.1634/theoncologist.2011-0384.

28. Frew PM, Saint-Victor DS, Isaacs MB, Kim S, Swamy GK, Sheffield JS, et al. Recruitment and retention of pregnant women into clinical research trials: an overview of challenges, facilitators, and best practices. Clin Infect Dis. 2014;59 Suppl 7(Suppl 7):S400-7.

29. Barrett NJ, Rodriguez EM, lachan R, Hyslop T, Ingraham KL, Le GM, et al. Factors associated with biomedical research participation within community-based samples across 3 National Cancer Institute-designated cancer centers. Cancer. 2020;126(5):1077-89. https://doi.org/10.1002/ cncr.32487.

30. Rivers D, August EM, Sehovic I, Lee Green B, Quinn GP. A systematic review of the factors influencing African Americans' participation in cancer clinical trials. Contemp Clin Trials. 2013;35(2):13-32. https://doi.org/10.1016/j.cct.2 013.03.007.

31. Canouï-Poitrine F, Lièvre A, Dayde F, Lopez-Trabada-Ataz D, Baumgaertner I, Dubreuil $\mathrm{O}$, et al. Inclusion of older patients with cancer in clinical trials: the
SAGE prospective multicenter cohort survey. Oncologist. 2019;24(12):e1351e9. https://doi.org/10.1634/theoncologist.2019-0166.

32. Caldieraro-Bentley AJ, Kelechi TJ, Treat-Jacobson D, Mueller M. Challenges in recruitment of persons with peripheral artery disease for exercise studies. J Vasc Nurs. 2018;36(3):111-20. https://doi.org/10.1016/j.jvn.2018.03.003.

33. Shepherd V, Wood F, Griffith R, Sheehan M, Hood K. Protection by exclusion? The (lack of) inclusion of adults who lack capacity to consent to research in clinical trials in the UK. Trials. 202019. p. 474.

34. Webb Hooper M, Asfar T, Unrod M, Dorsey A, Correa JB, Brandon KO, et al. Reasons for exclusion from a smoking cessation trial: an analysis by race/ ethnicity. Ethn Dis. 2019;29(1):23-30. https://doi.org/10.18865/ed.29.1.23.

35. Kaur G, Smyth RL, Powell CV, Williamson P. A survey of facilitators and barriers to recruitment to the MAGNETIC trial. Trials. 2016;17(1):607. https:// doi.org/10.1186/s13063-016-1724-3.

36. Rivera-Goba MV, Dominguez DC, Stoll P, Grady C, Ramos C, Mican JM. Exploring decision-making of HIV-infected Hispanics and African Americans participating in clinical trials. J Assoc Nurses AIDS Care. 2011;22(4):295-306. https://doi.org/10.1016/j.jana.2010.10.007.

37. Alahmad G. Informed consent in pediatric oncology: a systematic review of qualitative literature. Cancer Control. 2018;25(1):1073274818773720. https:// doi.org/10.1177/1073274818773720.

38. Brooks SE, Muller CY, Robinson W, Walker EM, Yeager K, Cook ED, et al. Increasing minority enrollment onto clinical trials: practical strategies and challenges emerge from the NRG oncology accrual workshop. J Oncol Pract. 2015;11(6):486-90. https://doi.org/10.1200/JOP.2015.005934.

39. Ezeugwu CO, Laird A, Mullins CD, Saluja DS, Winston RA. Lessons learned from community-based minority health care serving system participation in an NIH clinical trial. J Natl Med Assoc. 2011;103(9-10):839-44. https://doi. org/10.1016/S0027-9684(15)30438-7.

40. Regnante JM, Richie NA, Fashoyin-Aje L, Vichnin M, Ford M, Roy UB, et al. US cancer centers of excellence strategies for increased inclusion of racial and ethnic minorities in clinical trials. J Oncol Pract. 2019;15(4):e289-e99. https://doi.org/10.1200/JOP.18.00638.

41. Wallington SF, Dash C, Sheppard VB, Goode TD, Oppong BA, Dodson EE, et al. Enrolling minority and underserved populations in cancer clinical research. Am J Prev Med. 2016;50(1):111-7. https://doi.org/10.1016/j.a mepre.2015.07.036.

42. Waheed W, Husain N, Allen G, Atif N, Aseem S, Waquas A, et al. Recruitment strategies for British South Asians in 5 depression trials: a mixed method study. J Affect Disord. 2015;185:195-203. https://doi.org/10.1016/j.jad.2015. 06.046.

43. Horowitz CR, Sabin T, Ramos M, Richardson LD, Hauser D, Robinson M, et al. Successful recruitment and retention of diverse participants in a genomics clinical trial: a good invitation to a great party. Genet Med. 2019;21(10): 2364-70. https://doi.org/10.1038/s41436-019-0498-X.

44. Goff SL, Youssef Y, Pekow PS, White KO, Guhn-Knight H, Lagu T, et al. Successful strategies for practice-based recruitment of racial and ethnic minority pregnant women in a randomized controlled trial: the IDEAS for a Healthy Baby Study. J Racial Ethn Health Disparities. 2016;3(4):731-7. https:// doi.org/10.1007/s40615-015-0192-X.

45. Herrera AP, Snipes SA, King DW, Torres-Vigil I, Goldberg DS, Weinberg AD. Disparate inclusion of older adults in clinical trials: priorities and opportunities for policy and practice change. Am J Public Health. 2010;100 Suppl 1(Suppl 1):S105-12.

46. Siskind RL, Andrasik M, Karuna ST, Broder GB, Collins C, Liu A, et al. Engaging transgender people in NIH-funded HIV/AIDS clinical trials research. J Acquir Immune Defic Syndr. 2016;72 Suppl 3(Suppl 3):S243-7.

47. Ford ME, Siminoff LA, Pickelsimer E, Mainous AG, Smith DW, Diaz VA, et al. Unequal burden of disease, unequal participation in clinical trials: solutions from African American and Latino community members. Health Soc Work. 2013;38(1):29-38. https://doi.org/10.1093/hsw/hlt001.

48. Selak V, Crengle S, Elley CR, Wadham A, Harwood M, Rafter N, Bullen C, Pillai $A$, Arroll B, Rodgers A Recruiting equal numbers of indigenous and nonindigenous participants to a polypill' randomized trial Int J Equity Health 2013;12:44, 1, DOl: https://doi.org/10.1186/1475-9276-12-44.

49. Heller C, Balls-Berry JE, Nery JD, Erwin PJ, Littleton D, Kim M, et al. Strategies addressing barriers to clinical trial enrollment of underrepresented populations: a systematic review. Contemp Clin Trials. 2014;39(2):169-82. https://doi.org/10.1016/j.cct.2014.08.004.

50. Coakley M, Fadiran EO, Parrish LJ, Griffith RA, Weiss E, Carter C. Dialogues on diversifying clinical trials: successful strategies for engaging women and 
minorities in clinical trials. J Womens Health (Larchmt). 2012;21(7):713-6. https://doi.org/10.1089/jwh.2012.3733.

51. Maar MA, Beaudin V, Yeates K, Boesch L, Liu P, Madjedi K, et al. Wise practices for cultural safety in electronic health research and clinical trials with indigenous people: secondary analysis of a randomized clinical trial. J Med Internet Res. 2019;21(11):e14203. https://doi.org/10.2196/14203.

52. Duda C, Mahon I, Chen MH, Snyder B, Barr R, Chiles C, et al. Impact and costs of targeted recruitment of minorities to the National Lung Screening Trial. Clin Trials. 2011;8(2):214-23. https:/doi.org/10.1177/1740774510396742.

53. Falcon R, Bridge DA, Currier J, Squires K, Hagins D, Schaible D, Ryan R, Mrus J, GRACE Study Group. Recruitment and retention of diverse populations in antiretroviral clinical trials: practical applications from the gender, race and clinical experience study. J Womens Health (Larchmt) 2011;20(7):1043-1050, DOI: https://doi.org/10.1089/jwh.2010.2504.

54. Burlew AK, Weekes JC, Montgomery L, Feaster DJ, Robbins MS, Rosa CL, et al. Conducting research with racial/ethnic minorities: methodological lessons from the NIDA Clinical Trials Network. Am J Drug Alcohol Abuse 2011;37(5):324-32. https://doi.org/10.3109/00952990.2011.596973.

55. De las Nueces D, Hacker K, DiGirolamo A, Hicks LS. A systematic review of community-based participatory research to enhance clinical trials in racial and ethnic minority groups. Health Serv Res. 2012;47(3 Pt 2):1363-86. https://doi.org/10.1111/j.1475-6773.2012.01386.x.

56. Adams SA, Heiney SP, Brandt HM, Wirth MD, Khan S, Johnson H, et al. A comparison of a centralized versus de-centralized recruitment schema in two community-based participatory research studies for cancer prevention J Community Health. 2015;40(2):251-9. https://doi.org/10.1007/s10900-0149924-9.

57. Sacheck JM, Van Rompay MI, Olson EM, Chomitz VR, Goodman E, Gordon $\mathrm{CM}$, et al. Recruitment and retention of urban schoolchildren into a randomized double-blind vitamin D supplementation trial. Clin Trials. 2015; 12(1):45-53. https://doi.org/10.1177/1740774514556551.

58. Zimmerman LP, Goel S, Sathar S, Gladfelter CE, Onate A, Kane LL, et al. A novel patient recruitment strategy: patient selection directly from the community through linkage to clinical data. Appl Clin Inform. 2018;9(1):11421. https://doi.org/10.1055/s-0038-1625964.

59. Barnett J, Aquilar S, Brittner M, Bonuck K. Recruiting and retaining lowincome, multi-ethnic women into randomized controlled trials: successful strategies and staffing. Contemp Clin Trials. 2012;33(5):925-32. https://doi. org/10.1016/j.cct.2012.06.005.

60. Lavender V, Gibson F, Brownsdon A, Fern L, Whelan J, Pearce S. Health professional perceptions of communicating with adolescents and young adults about bone cancer clinical trial participation. Support Care Cancer. 2019;27(2):467-75. https://doi.org/10.1007/s00520-018-4337-4.

61. Andreae MH, Nair S, Gabry JS, Goodrich B, Hall C, Shaparin N. A pragmatic trial to improve adherence with scheduled appointments in an inner-city pain clinic by human phone calls in the patient's preferred language. J Clin Anesth. 2017;42:77-83. https://doi.org/10.1016/j.jclinane.2017.08.014.

62. Wang JH, Sheppard VB, Liang W, Ma GX, Maxwell AE. Recruiting Chinese Americans into cancer screening intervention trials: strategies and outcomes. Clin Trials. 2014;11(2):167-77. https://doi.org/10.1177/1740774513 518849

63. Napoles A, Cook E, Ginossar T, Knight KD, Ford ME. Applying a conceptual framework to maximize the participation of diverse populations in cancer clinical trials. Adv Cancer Res. 2017;133:77-94. https://doi.org/10.1016/bs.a cr.2016.08.004

64. Ramsey TM, Snyder JK, Lovato LC, Roumie CL, Glasser SP, Cosgrove NM, et al. Recruitment strategies and challenges in a large intervention trial: Systolic Blood Pressure Intervention Trial. Clin Trials. 2016;13(3):319-30. https://doi.org/10.1177/1740774516631735.

65. Sturgeon KM, Hackley R, Fornash A, Dean LT, Laudermilk M, Brown JC, et al. Strategic recruitment of an ethnically diverse cohort of overweight survivors of breast cancer with lymphedema. Cancer. 2018;124(1):95-104. https://doi. org/10.1002/cncr.30935.

66. Wisk LE, Nelson EB, Magane KM, Weitzman ER. Clinical trial recruitment and retention of college students with type 1 diabetes via social media: an implementation case study. J Diabetes Sci Technol. 2019;13(3):445-56. https://doi.org/10.1177/1932296819839503.

67. Vander Stoep A, Myers K. Methodology for conducting the children's attention-deficit hyperactivity disorder telemental health treatment study in multiple underserved communities. Clin Trials. 2013;10(6):949-58. https://doi. org/10.1177/1740774513494880.
68. Amorrortu RP, Arevalo M, Vernon SW, Mainous AG 3rd, Diaz V, McKee MD, et al. Recruitment of racial and ethnic minorities to clinical trials conducted within specialty clinics: an intervention mapping approach. Trials. 2018;19(1): 115. https://doi.org/10.1186/s13063-018-2507-9.

69. Koziol-McLain J, McLean C, Rohan M, Sisk R, Dobbs T, Nada-Raja S, et al. Participant recruitment and engagement in automated eHealth trial registration: challenges and opportunities for recruiting women who experience violence. J Med Internet Res. 2016;18(10):e281. https://doi.org/1 0.2196/jmir.6515.

70. Smorenburg AJ, Oosterman BJ, Grobbee DE, Bonten MJ, Roes KC. Effects of recruitment strategies and demographic factors on inclusion in a large scale vaccination trial in adults 65 years and older. Vaccine. 2014;32(25):2989-94. https://doi.org/10.1016/j.vaccine.2014.03.081.

71. Tilley BC, Mainous AG 3rd, Elm JJ, Pickelsimer E, Soderstrom LH, Ford ME, et al. A randomized recruitment intervention trial in Parkinson's disease to increase participant diversity: early stopping for lack of efficacy. Clin Trials. 2012;9(2):188-97. https://doi.org/10.1177/1740774512436881.

72. Freedman RA, Dockter TJ, Lafky JM, Hurria A, Muss HJ, Cohen HJ, et al. Promoting accrual of older patients with cancer to clinical trials: an alliance for clinical trials in oncology member survey (A171602). Oncologist. 2018; 23(9):1016-23. https://doi.org/10.1634/theoncologist.2018-0033.

73. Yu SH, Gumport NB, Mirzadegan IA, Mei YJ, Hein K, Harvey AG. Addressing the challenges of recruitment and retention in sleep and circadian clinical trials. Behav Sleep Med. 2020;18(1):23-34. https://doi.org/10.1080/15402 002.2018.1518230

74. Jennings CG, MacDonald TM, Wei L, Brown MJ, McConnachie L, Mackenzie IS. Does offering an incentive payment improve recruitment to clinical trials and increase the proportion of socially deprived and elderly participants? Trials. 2015;16(1):80. https://doi.org/10.1186/s13063-015-0582-8.

\section{Publisher's Note}

Springer Nature remains neutral with regard to jurisdictional claims in published maps and institutional affiliations.

\section{Ready to submit your research? Choose BMC and benefit from:}

- fast, convenient online submission

- thorough peer review by experienced researchers in your field

- rapid publication on acceptance

- support for research data, including large and complex data types

- gold Open Access which fosters wider collaboration and increased citations

- maximum visibility for your research: over $100 \mathrm{M}$ website views per year

At BMC, research is always in progress.

Learn more biomedcentral.com/submissions 